\title{
CINCO DÉCADAS DE LOGÍSTICA EMPRESARIAL E ADMINISTRAÇÃO DA CADEIA DE SUPRIMENTOS NO BRASIL
}

Claude Machline claude.machline@fgv.br

Professor da Escola de Administração de Empresas de São Paulo, Fundação Getulio Vargas - São Paulo - SP, Brasil

\section{INTRODUÇ̃̃̃O}

O desenvolvimento da logística empresarial e da administração da cadeia de suprimentos no Brasil transcorreu de modo semelhante à sua evolução nos Estados Unidos, com alguns anos de defasagem em relação aos progressos norte-americanos. Em síntese, o tópico transporte, que era o foco do interesse nas décadas de 1950 e 1960, foi ampliado nas décadas de 1970 e 1980, transformandose em nova área de saber, a logística empresarial. Essa função administrativa, numa visão mais abrangente do que a que antes vigorava, incorporava ao transporte a gestão dos estoques, o armazenamento, os depósitos, a informação e a comunicação. Por sua vez, a partir dos anos 1990, em novo salto conceitual, prevaleceu a visão da cadeia de suprimentos, que constituía um alargamento (e também um alongamento) da noção de logística empresarial, estendendo essa última a toda a cadeia de fornecedores, a montante, e a toda a cadeia de clientes, a jusante da empresa.

\section{TRANSPORTE DOS MATERIAIS}

O transporte dos materiais - matérias-primas, produtos em fabricação e produtos acabados - sempre mereceu atenção por parte dos responsáveis pela gestão industrial, por ser assunto estreitamente ligado ao leiaute e à estrutura física do prédio e por ter implicações na produtividade, na qualidade, na segurança no local de trabalho e nos custos da operação. Todos os manuais de administração da produção da época (Maynard, Ireson e Grant) dedicavam vários capítulos ao prédio industrial, ao arranjo físico e ao transporte interno dos materiais (material handling).

Em vista dos imperativos operacionais e dos custos envolvidos, o transporte das matérias-primas, dos componentes e dos demais insumos, desde suas fontes até a fábrica, sempre foi tópico essencial da administração da produção e constituiu um dos fatores mais relevantes para a localização da indústria. Pelas mesmas razões, o escoamento dos produtos acabados até os centros de consumo (distribuição) também erigia-se numa consideração de máxima importância para a escolha da localização da empresa.

A escala crescente das operações nas décadas do pós-guerra, de 1945 em diante; o advento de novos equipamentos e tecnologias de transporte, tais como a empilhadeira de garfos, o transelevador, a paletização, as correias transportadoras, o contêiner; e os graus crescentes de mecanização e automação exigiam que se desse um nível de atenção sempre maior ao transporte, tanto de entrada (input) quanto interno e de saída (output). A engenharia de produção e a engenharia econômi$\mathrm{ca}$, que analisam os equipamentos e permitem determinar os mais adequados, técnica e economicamente, encontravam, na área de transporte, um fértil campo de aplicações.

O crescimento econômico do País, sua modernização, a oficialização do nascimento da indústria automobilística nacional (1957), a construção das primeiras estradas de rodagem (via Anchieta, via Dutra) chamavam a atenção do público para uma área carente, a deficiente infraestrutura rodoviária.

A advertência do Presidente Washington Luiz, pronunciada 30 anos antes, começou finalmente a ser ouvida pelos governos federal e estaduais: "Governar é abrir estradas". 
Atendendo à demanda do mercado, a Editora Abril lançou, em 1963, a primeira revista técnica dedicada ao setor, Transporte Moderno.

Algumas empresas privadas investiram, nos anos 1960, em iniciativas pioneiras na área de transportes. A Viação Cometa montou linhas de ônibus modernos, rápidos, limpos, confortáveis, entre algumas capitais do País. Os motoristas eram cuidadosamente selecionados, inclusive no aspecto psicológico. Para evitar que dormissem nos longos percursos noturnos, eram obrigados a se recolher em dormitórios da empresa algumas horas antes de cada viagem. A Cometa também foi pioneira no controle do consumo de combustível, lubrificante, pneus e peças de cada veículo, calculando seu desempenho e custo individual. A Real Aerovias e a Varig demonstraram às demais empresas de transporte a necessidade e as vantagens de uma bem-organizada manutenção. Estimuladas por esses exemplos, as transportadoras começaram a adotar essas boas práticas gerenciais, antes inéditas na cultura das empresas. Mais tarde, empresas públicas de transporte, como a Companhia Metropolitana de Transporte Coletivo de São Paulo (CMTC), com sua frota de $10 \mathrm{mil}$ ônibus, tornaram-se adeptos modelares dos melhores sistemas de manutenção e controle de frotas.

Outras iniciativas precursoras da década de 1960 foram: a criação do autotrem, isto é, uma composição na qual, colocados sobre vagões-plataformas, os caminhões são transportados por trem, uma inovação do empresário Walter Lorch, controlador da Translor; a tentativa de transportar automóveis zero-quilômetro de São Bernardo do Campo para as demais regiões do País por navios de cabotagem roll-on roll-off; a façanha de distribuir regularmente botijões de gás de petróleo liquefeito de porta a porta para centenas de milhares de domicílios.

São Paulo estava se tornando a terceira maior cidade do mundo. Empresas tinham que distribuir diariamente milhares de produtos a milhões de pessoas. O mero vulto dessas operações, realizadas apesar de obstáculos de todo tipo, representava uma façanha administrativa, independentemente da obtenção de padrões aceitáveis de frequência, pontualidade e regularidade.

Em 1965, o governo cria, no Ministério dos Transportes, a Empresa Brasileira de Planejamento de Transportes (Geipot), um think tank dos macroproblemas nacionais de transporte, cujos conceituados estudos tornaram-na uma referência nacional no assunto.

\section{NASCIMENTO DA LOGÍSTICA EMPRESARIAL}

Nos Estados Unidos, na década de 1960, uma nova visão gerencial estava alterando a percepção anteriormente dominante acerca da área de transporte. Notava-se que a tarefa de entregar o produto na quantidade certa, no local certo, na hora certa, incluía mais do que o transporte em si. A integração da gestão dos estoques, do armazenamento, das compras, da produção, da comunicação e da informação seria necessária para abastecer corretamente, ao mínimo custo possível. Em vez da única variável transporte, a equação do abastecimento necessitava a introdução de mais variáveis. Os militares, de longa data, vinham utilizando o termo logística para designar o suprimento de munições e provisões às tropas nos campos de batalha. Os resultados da logística militar, que havia contribuído decisivamente para a vitória dos aliados na Segunda Guerra Mundial, incitavam as empresas a adotar seus ensinamentos. Também influiu na aceitação da nova visão logística a divulgação das técnicas de pesquisa operacional. Essa área propunha a quantificação da gestão, por meio da criação de modelos matemáticos para solução dos problemas administrativos complexos, como, em especial, os de transporte. Um problema típico era, por exemplo: que fábricas ou que filiais deveriam abastecer quais mercados, para minimizar os custos totais da operação?

As técnicas quantitativas usavam algoritmos, como em gestão de estoques, programação linear, teoria de filas de espera, programação de projetos; heurísticas, como em programação da produção, roteirização de frotas, alocação de recursos; ou simulação de modelos, para problemas complexos demais para poderem ser resolvidos por algoritmos.

A teoria dos sistemas popularizara o conceito de otimização do sistema, visto como um todo, por oposição à subotimização de uma ou algumas de suas partes. Se um sistema for composto de duas partes, digamos: transporte e estoques, e se o gestor só pensar na otimização do transporte, reduzindo, por exemplo, o custo do transporte, mas aumentando o estoque, ele estará subotimizando, em vez de otimizar. Os trabalhos de Jay Forrester, no Massachussets Institute of Technology (MIT), re- 
lativos à dinâmica dos sistemas, divulgados a partir de 1958, analisavam a influência da alteração da demanda do consumidor final sobre a disponibilidade dos produtos na fábrica. Exerceram forte influência sobre a divulgação da nova abordagem logística, em que as variáveis estão interligadas.

Os títulos dos livros publicados mostram a evolução do pensamento gerencial, do transporte para a nova área, que, por tradição, guardou a designação de logística, mas, por necessidade de diferenciação do campo militar, denominou-se logística empresarial (business logistics). Em 1957, os professores George P. Baker e Gayton F. Germane escreveram um livro de 523 páginas, Case Problems in Transportation Management. Entre 1960 e 1966, o professor Karl M. Ruppenthal, da Graduate School of Business da Stanford University, editou cinco volumes de trabalhos relativos a transporte, demoninados Revolution in Transportation, Challenge in Transportation, Transportation Frontiers, Issues in Transportation Economics e Transportation and Tomorrow, num total de 1.126 páginas. Todavia, em 1963, editou um volume de 173 páginas, com o título New Dimensions in Business Logistics; e outro, em 1968, Business Logistics in American Industry, de 403 páginas. A expressão business logistics estava fazendo sua entrada em cena.

Em 1963, J. L. Heskett, igualmente da Stanford University, editava uma obra de 146 páginas sobre Business Logistics: Appraisal and Prospect.

Em 1964, veio à luz o primeiro livro didático sobre o tópico em foco, de autoria de J. L. Heskett, Robert M. Ivie e Nicholas A.
Glaskowsky Jr, os dois últimos da Ohio State University, com o título Business Logistics, Management of Physical Supply and Distribution.

Os livros de logística empresarial sucedem-se. Em 1968, aparece o conhecido livro-texto de John F. Magee, Industrial Logistics; Analysis and Management of Physical Supply and Distribution Systems.

Ronald H. Ballou produz, em 1978, seu Basic Business Logistics, Transportation, Materials Management, Physical Distribution.

O primeiro livro nacional de logística, da autoria do então professor da Fundação Getulio Vargas de São Paulo Reginald Uelze, saiu do prelo em 1974, com o título Logística Empresarial, uma Introdução à Administração dos Transportes. Deve-se creditar também ao professor Uelze, secundado por colegas de Departamento de Produção e Operações Industriais da FGV-EAESP, notadamente os professores Kurt E. Weil e Wolfgang Schoeps, a iniciativa de convidar os professores Germane e Ruppenthal para ministrar palestras, no ano de 1972, sobre logística empresarial, em São Paulo. Foram as primeiras conferências proferidas no Brasil sobre o tema.

Entre as diversas instituições que começaram a efetuar pesquisas, consultorias e publicações nessa fase, destacam-se o Instituto de Movimentação e Armazenamento de Materiais (IMAM), em São Paulo, e o Centro de Estudos em Logística (CEL), do Instituto de Pós-graduação e Pesquisa em Administração de Empresas (Coppead), fundado em 1991, da Universidade Federal do Rio de Janeiro.

\section{CADEIA DE SUPRIMENTOS}

Assim como a logística empresarial ampliou o conceito de transporte, adicionando-lhe as dimensões de compras, gestão de estoques, armazenamento, comunicação, informação e administração, assim também uma nova concepção, chamada cadeia de suprimentos (supply chain), surgiu na comunidade empresarial e veio enriquecer o ponto de vista logístico.

Embora se debata ainda intensamente se a noção de cadeia de suprimento acrescenta algo substantivo ao conteúdo da logística, a definição dada pelo Supply Chain Council (2002) joga alguma luz sobre a matéria: "cadeia de suprimento abrange todos os esforços envolvidos na produção e na entrega de um produto final desde o fornecedor do fornecedor até o cliente do cliente".

Enquanto a logística concentra-se nas operações da própria empresa, a cadeia de suprimentos olha desde o início até os elos finais da corrente de fornecedores e clientes. E com uma visão mais ampla e panorâmica do que a visão logística. Além da preocupação de todas as empresas com o que ocorre ao longo de toda a sua cadeia, é necessário um intenso grau de colaboração entre empresas ao longo da cadeia de suprimentos para que se atinja maior eficiência. Reuniões periódicas entre cliente - por exemplo, um supermercado - e seus fornecedores-fabricantes de mantimentos são efetuadas a fim de promover essa integração, sobretudo compartilhando informações relativas à demanda e aos estoques e adotando uma atitude amigável em vez de uma postura de confronto.

Essa filosofia tem recebido o nome de Efficient Consumer Response (ECR) e seu objetivo oficial é aumentar o lucro da opera- 
ção ao longo da cadeia, resultando também na redução do custo do produto para o consumidor final. Os esforços colaborativos são ainda mais cruciais nas promoções e nos lançamentos de novos produtos. Pretende-se aumentar o giro dos estoques, reduzir as faltas nas prateleiras e facilitar as entregas.

A globalização, que se intensificou nas últimas décadas do século XX, força as empresas a aceitar a ideia de que estão inseridas numa cadeia de suprimentos, de extensão geográfica considerável.

A literatura técnica relativa a cadeias de suprimentos torna-se expressiva. Livros e artigos que anteriormente só traziam o termo transporte no seu título, agora, sempre nele incluem as palavras logística e supply chain. Um exemplo é um livro-texto clássico: Logistical Management; the Integrated Supply Chain Process, de Donald J. Bowersox e David J. Closs (1996), da Michigan State University, uma instituição de ensino proeminente nessa esfera de saber.

Proliferam revistas técnicas que tratam de transporte, logística e cadeias de suprimentos, podendo-se citar, entre outras, a Revista Tecnologística (1995); a Global, Comércio Exterior e Logistica (2002); a Today Logistics and Supply Chain (2006). São criadas numerosas associações profissionais, tais como a Associação Brasileira de Logística

\section{Figura 1 - A Era do Transporte, até 1950 isolamento das empresas}

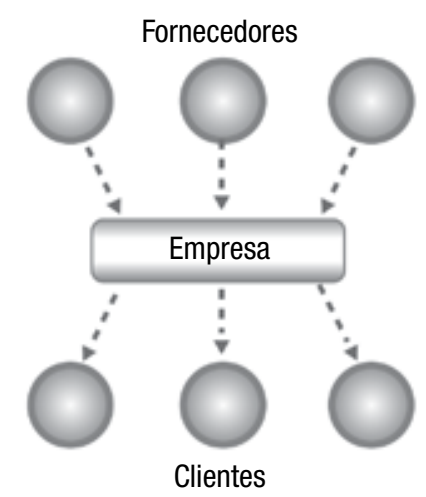

\section{Figura 3 - A Era da Cadeia de Suprimentos, 1970 - 2000 - visão integrada}

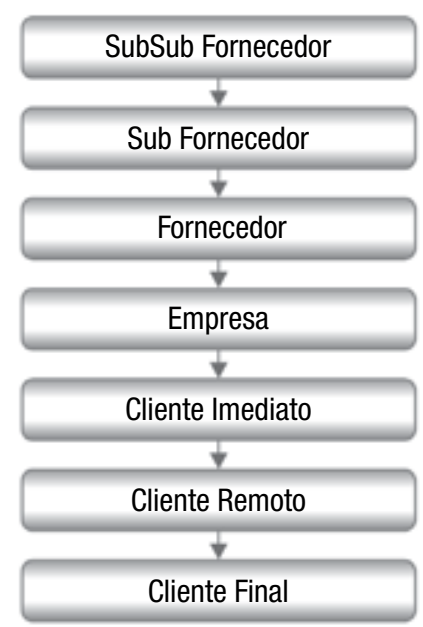

\section{Figura 2 - A Era da Logística Empresarial,} 1950 - 1970 - visão sistêmica

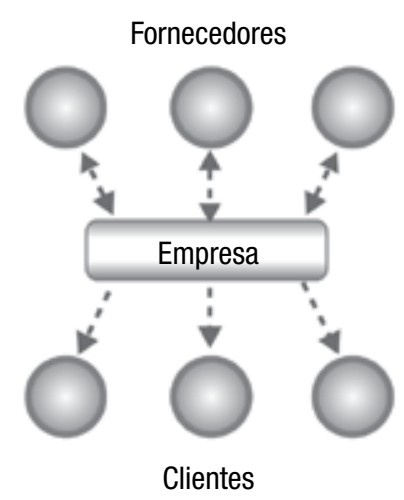

\section{Figura 4 - A Era das Redes de Suprimentos, 2000 - visão global}

Rede de fornecedores e Subfornecedores

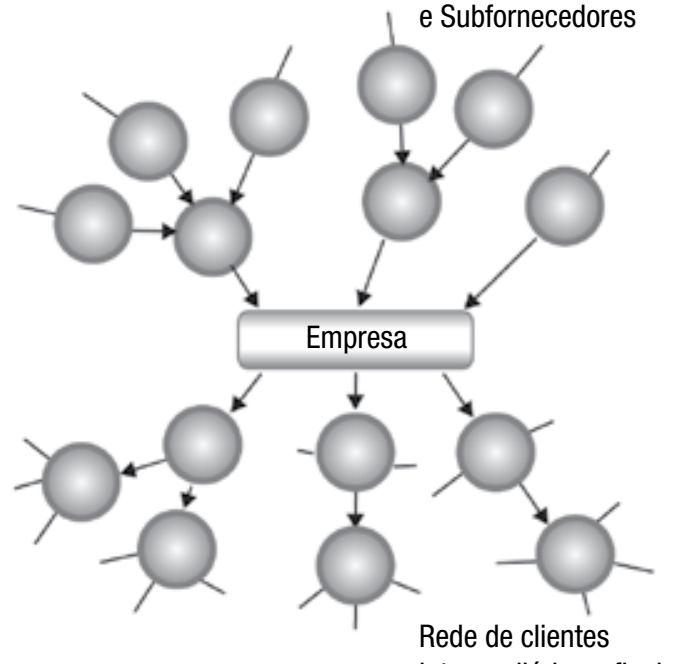

intermediários e finais 
(Aslog - 1989) e a Associação Brasileira de Movimentação e Logística (ABML - 1997).

Multiplicam-se cursos de administração de logística e cadeias de suprimentos.

A FGV-EAESP cria, em 2005, um Centro de Excelência em Logística e Cadeias de Abastecimento (Celog), para realização de pesquisas e publicações na área.

O Simpósio de Administração da Produção, Logística e Operações Internacionais (Simpoi), da FGV-EAESP, escolheu, para designar o tema do seu evento anual, em 2008, o título "Cadeias de Suprimentos Sustentáveis", associando dois temas administrativos da maior relevância, cadeias de suprimento e sustentabilidade.

As empresas nacionais ainda se encontram no limiar dessa era de colaboração entre os membros da cadeia de suprimentos. Receiam desvendar dados confidenciais aos fornecedores, que podem espalhálos aos seus concorrentes. Como declarou um participante das reuniões de grupo congregando elos da cadeia supermercadista: "Se é difícil o entendimento dentro da empresa, entre compras, vendas, produção, finanças, logística e outros setores, como vamos conseguir nos entender entre empresas?" Outro participante, instado a expor ao grupo sua metodologia de previsão de demanda, explicou sua reticência nas seguintes palavras: "Como posso falar abertamente? Tenho um fornecedor sentado na minha frente, um cliente à esquerda, um concorrente atrás de mim e meu chefe à direita".

As Figuras de 1 a 4 mostram graficamente a evolução dos conceitos aqui expostos, desde a era do transporte (Figura 1) até a era das redes de suprimentos (Supply Network, Figura 4), passando pela era da logística empresarial (Figura 2) e pela era da cadeia de suprimentos (Figura 3), numa visão sempre mais ampla, sistêmica e global.

\section{CONCLUSÃO}

Os tópicos de logística e cadeias de suprimentos estão entre os que mais têm recebido atenção por parte de administradores. Assuntos tradicionalmente ensinados sob os nomes de gestão de materiais, armazenamento, administração de almoxarifados, transportes hoje são englobados sob a denominação genérica de logística ou cadeias de suprimento. Apesar de essa tendência já se ter manifestado por várias décadas, muitos estudiosos consideram que os novos termos não passam de uma criação semântica, que a expressão cadeia de suprimento é apenas um elegante sinônimo de logística e que logística, por sua vez, é um lindo modismo para dizer transporte. Outros, esquecidos de que a logística abrange a entrada de materiais na empresa (inputs), o transporte interno (material handling), a saída (outputs) e a reversa, ou seja, a reciclagem (reverse), reduzem a logística à distribuição dos bens finais.

Algumas empresas de grande porte estão criando o cargo de Diretor de Cadeias de Suprimento, com total responsabilidade sobre o abastecimento da empresa e o fornecimento aos clientes. Entenderam, como se acabou descrevendo neste breve histórico, que os nomes de logística e cadeia de suprimento não constituem apenas modas terminológicas, mas encerram conceitos inovadores de integração de funções e interligação entre empresas.

\section{REFERÊNCIAS}

BALLOU, R. H. Gerenciamento da cadeia de suprimentos: planejamento, organização e logística empresarial. Porto Alegre: Bookman, 2001.

BALLOU, R. H. Logística empresarial: transportes, administração de materiais e distribuição física. São Paulo: Atlas, 2010.

BARBIERI, J. C; MACHLINE, C. Logistica hospitalar, teoria e prática. 2. ed. São Paulo: Saraiva, 2009.

CORRÊA, H. L. Changes in the role of production and operations management in the new economy. Journal of Operations and Supply Chain Management (JOSCM), v. 1, n. 1, p. 1-11, 2008.

DIAS, M. A. P. Administração de materiais, uma abordagem logística. 5. ed. São Paulo: Atlas, 2006.

FIGUEIREDO, K. F; FLEURY, P. F; WANKE, P. Logística e gerenciamento da cadeia de suprimentos: planejamento do fluxo de produtos e dos recursos. São Paulo: Atlas, 2003.

MAGEE, J. F. Logística industrial: análise e administração dos sistemas de suprimentos e distribuição. São Paulo: Pioneira, 2001.

NOVAES, A. G. Logística e gerenciamento da cadeia de distribuição. Rio de Janeiro: Campus, 2001.

PIRES, S. R. I. Gestão da cadeia de suprimentos: conceitos, estratégias, práticas e casos. São Paulo: Atlas, 2004. 